\title{
PENGARUH SUHU DAN LAMA TEMPER TERHADAP KEKERASAN DAN TAHAN AUS BAJA HQ 760
}

\author{
Syamsuir \\ Jurusan Teknik Mesin, Fakultas Teknik, Universitas Negeri Jakarta \\ e-mail: syamsuir@unj.ac.id
}

\begin{abstract}
ABSTRAK
Peneltian ini bertujuan untuk mengetahui pengaruh temperature tempering dan lama waktu tahan temper terhadap kekerasan dan daya tahan aus baja HQ 760. Pelaksanaan penelitian adalah sebagai berikut; specimen uji dipanasakan pada suhu austenisasi $\left(850^{\circ} \mathrm{C}\right)$ selama 30 menit, selanjutnya didinginkan dengan cepat (quenching) dalam media oli dan kemudian distemper pada suhu 150, 200, 250, 350, dan $600{ }^{\circ} \mathrm{C}$ masing-masing selama 30, 60 dan 180 menit. Pengujian kekerasan dilakukan dengan metode indentasi Vickers, besarnya beban penekan yang diberikan adalah $50 \mathrm{~kg}$. pengujian daya tahan aus dilakuan dengan metode dray sliding test.

Hasil penelitian menunjukan terdapat pengaruh temperature temper terhadap kekerasan baja HQ760. Kekerasan terbaik diperoleh pada suhu temper antara $250^{\circ} \mathrm{C}$ sampai dengan $250^{\circ} \mathrm{C}$. Sementara itu daya thana aus berbanding lurus dengan angka kekerasan benda uji. Semakin tinggi angka kekerasan benda uji, maka semakin sedikit jumlah masa benda uji yang hilang akibat terjadi gesekan antara permukaan benda uji dengan permukaan pelat penggesek.
\end{abstract}

Kata kunci: suhu dan lama temper, kekerasan, daya tahan aus

\section{PENDAHULUAN}

Baja dapat dikeraskan sehingga memiliki ketahanan aus, peningkatan ketangguhan, dan nilai kekerasannya meningkat dengan inti yang tetap ulet. Hal tersebut bisa didapat dengan perlakuan panas yang tepat. Pengerasan (hardening) adalah proses pemanasan baja sampai temperatur Austenite lalu diikuti dengan pendingan yang cepat dengan mencelupkannya waktu pengerasan. Quenching menghasilkan struktur martensit yang sangat keras namun juga getas dan tidak cocok untuk digunakan. Melalui temper, kekerasan dan kegetasan dapat diturunkan sampai memenuhi persyaratan penggunaan. Kekerasan turun,kekuatan tarik akan turun pula sedangkan keuletan dan ketangguhan baja akan meningkat. Proses temper dilakukan dengan memanaskan kembali baja pada temperatur dibawah temperatur kiritis disusul dengan pendinginnan. Penurunan kekerasan berbanding lurus dengan remperatur temper dan waktu tahan. Proses temper dimungkinkan olek karena stuktur martensit tidak stabil.Temper akan menyebabkan perubahan martensit menjadi campuran ferrite-sementit, (quenching) ke dalam media pendingin tertentu. Kekerasan yang dapat dicapai tergantung pada laju pendinginan, kadar karbon dan ukuran benda pada baja paduan, jenis dan jumlah paduan akan memperngaruhi kemampuan pengerasan.

Tempering dilakukan dengan tujuan untuk menghilangkan tegangan permukan yang ditimbulkan pada

dan memberikan sifat tangguh pada baja. Baja HQ760 adalah termasuk salah satu jenis baja paduan, dengan komposisinya adalah; 0,505\% C; 0,558\% Mn; 0,017\% P; $0,03 \% \mathrm{~S}$ dan $0,169 \% \mathrm{Si}$. Pada penelitian, dengan perlakuan panas quenching dan dilanjutkan dengan tempering akan ditingkatkan kekeran dan daya tahan aus terhadap gesekan pada baja ini.

\section{METODE PENELITIAN}

Penelitian ini adalah penelitian eksperimen, dimana sampel (bahan uji) baja HQ 750 diberikan perlakuan panas quenching lalu dilanjutkan dengan perlakuan panas tempering, sepertiyang ditunjukan pada diagram alir penelitian. 


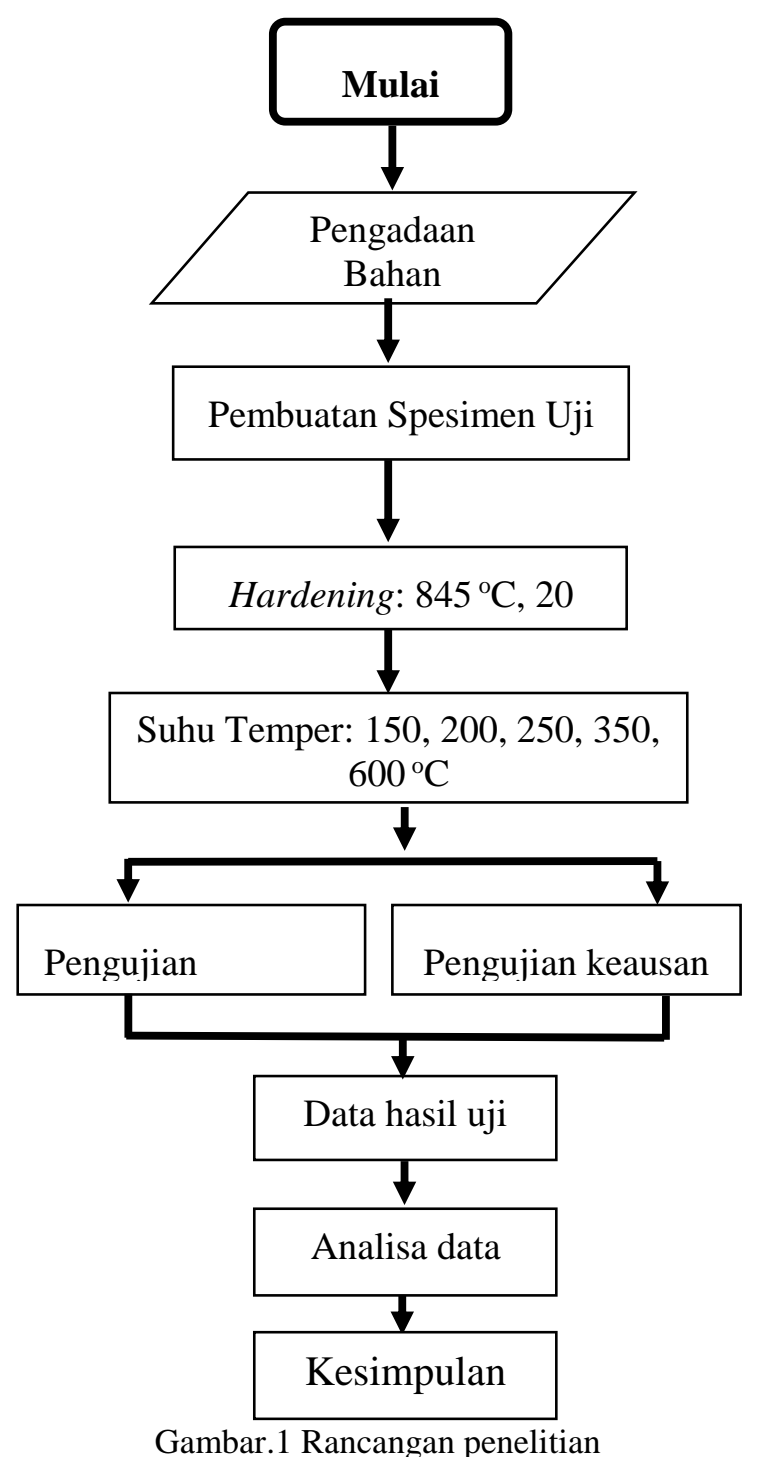

Pengujian kekerasan dalam penelitian ini menggunakan skala kekerasan Vickers (VHN). Pengujian Vickers menggunakan indentor berbentuk piramida, pembebanan diberikan secara perlahan tanpa adanya beban kejut/tiba-tiba dan ditahan untuk 1015 detik. Setelah beban di angkat, kedua diagonal bekas injakan/penekanan diukur, kemudian dirata-ratakan. Kekerasan Vickers (VHN) dapat dihitung dengan menggunakan persamaan:

$V H N=\frac{1,8544 F}{d^{2}}\left(\mathrm{kgf} / \mathrm{mm}^{2}\right)$ di mana $F$ adalah beban dalam $\operatorname{kgf}$ dan $d$ adalah diagonal bekas injakan dalam mm.

Pengujian keausan diuji dengan metoda adhesive wear (type rotating dry sliding), dimana benda uji (test piece) digesekan dengan disk yang berputar (revolving disk) dengan tebal disk $\mathrm{B}$, diameter $2 \mathrm{r}$, beban $\mathrm{P}$, bidang kontak S, membentuk bekas gerusan(groove) dengan kedalaman $\mathrm{h}$, dan lebar b, tampa adanya pelumasan. Skema pengujian ini ditunjukan pada gambar 2 . 


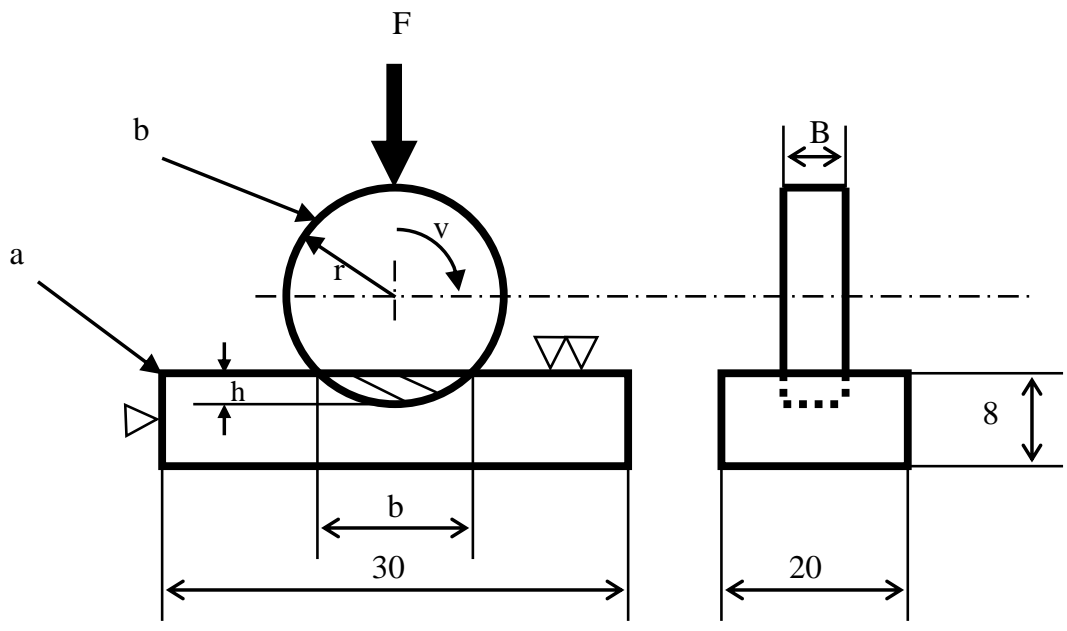

Gambar 2. Skema pengujian keausan (adhesive wear)

Keausan sebagai berkurangnya masa atau volume benda uji setelah mengalami penggesekan (pengerusan) akibat kontak antara revolving disk dan benda uji dapat dihitung dengan persamaan berikut :

$$
W=\frac{B \cdot b^{3}}{12 r}
$$

dengan b lebar gerusan diukur dengan mikroskop setelah pengujian berlangsung.

\section{HASIL PENELITIAN DAN} PEMBAHASAN

\section{A. Pengujian kekerasan}

Pengujian kekerasan dilakukan pada semua benda uji yang sudah mendapat perlakuan quenching dan kemudian diberikan perlakuan tempering dengan beberapa variasi temperature temper dan waktu tahan. Hasil pengujian di bandingkan dengan kekerasan benda uji yang hanya diberikan perlakuan quenching saja dan kekerasan raw material.

Pengujian kekerasan menggunakan metode indentasi Vickers. Penekanan dilakukan pada beberapa titik pada permukaan benda uji. Data pengujian berupa diagonal bekas indentor yang kemudian dianalisa dengan persamaan Vickers untuk mendapatkan harga kekerasannya
Hasil pengujian, dalam bentuk nilai kekerasan Vickers (Vickers Hardness Number, VHN ) dapat di lihat seperti pada table 1. Berdasarkan data yang diperoleh dari pengujian kekerasan tersebut, jelas terlihat peningkatan yang signifikan dari kekerasan baja HQ 760 dari kekerasan awalnya. Dimana terjadi peningkatan kekerasan sebesar $322 \%$. Laju peningkatan kekerasan yang terlalu signifikan tersebut akan mengakibatkan material terbut menjadi sangat keras dan getas. Oleh karena itu diberikan perlakuan tempering untuk menurunkan tingkat kekerasan baja tersebut sehingga tetap menghasilkan baja yang cukup keras dengan inti yang ulet. Benda uji baja HQ 760 setelah diberikan perlakuan tempering dengan beberapa variasi suhu temper dan waktu lalu diuji tingkat kekerasannya. 
Tabel 1. Hasil pengujian kekerasan

\begin{tabular}{|c|c|c|c|}
\hline $\begin{array}{c}\text { PERLAKU } \\
\text { AN }\end{array}$ & $\begin{array}{l}\text { SUHU } \\
\left({ }^{\circ} \mathrm{C}\right)\end{array}$ & $\begin{array}{c}\text { WAKTU } \\
\text { tahan } \\
\text { ( menit ) }\end{array}$ & VHN \\
\hline $\begin{array}{c}\text { BHN } \\
\text { DASAR }\end{array}$ & & & $\begin{array}{c}185.10 \\
4\end{array}$ \\
\hline $\begin{array}{c}\text { HARDENI } \\
\text { NG }\end{array}$ & 845 & 30 & $\begin{array}{c}593.63 \\
7 \\
\end{array}$ \\
\hline \multirow[b]{3}{*}{$\mathrm{T}$} & \multirow{3}{*}{150} & 30 & $\begin{array}{c}542.86 \\
7 \\
\end{array}$ \\
\hline & & 60 & 496.21 \\
\hline & & 180 & $\begin{array}{c}456.11 \\
6\end{array}$ \\
\hline $\mathrm{E}$ & \multirow{3}{*}{200} & 30 & $\begin{array}{c}472.51 \\
8\end{array}$ \\
\hline \multirow[t]{2}{*}{ M } & & 60 & $\begin{array}{c}384.82 \\
4\end{array}$ \\
\hline & & 180 & $\begin{array}{c}352.97 \\
7\end{array}$ \\
\hline $\mathrm{E}$ & \multirow{3}{*}{250} & 30 & $\begin{array}{c}413.30 \\
3 \\
\end{array}$ \\
\hline \multirow[t]{8}{*}{$\mathrm{R}$} & & 60 & $\begin{array}{c}316.15 \\
1\end{array}$ \\
\hline & & 180 & $\begin{array}{c}297.94 \\
7\end{array}$ \\
\hline & \multirow{3}{*}{350} & 30 & $\begin{array}{c}405.89 \\
8\end{array}$ \\
\hline & & 60 & $\begin{array}{c}278.44 \\
9\end{array}$ \\
\hline & & 180 & $\begin{array}{c}303.26 \\
6\end{array}$ \\
\hline & \multirow{3}{*}{600} & 30 & $\begin{array}{c}242.65 \\
5\end{array}$ \\
\hline & & 60 & $\begin{array}{c}242.92 \\
5\end{array}$ \\
\hline & & 180 & $\begin{array}{c}236.55 \\
4 \\
\end{array}$ \\
\hline
\end{tabular}

\section{B. Pengujian keausan}

Pengujian keausan menghasil bekas gerusan seperti yang tampak pada gambar 3, dengan menggunakan mikroskop lebar gerusan (b) dapat diukur. Gerusan tersebut menunjukan sejumlah masa material uji yang hilang akibat gesekan antara benda uji dengan permukaan alat uji gerus.
Diharapkan setelah mendapat perlakuan tempering tersebut, penurunan tingkat kekerasan baja yang sudah mendapat perlakuan quenching tadi tidak terjadi penurunan kekerasan yang terlalu tajam. Oleh karena itulah

maka perlakuan tempernya dilakukan dengan beberapa variasi suhu temper. dan lama waktu tahan.

Hasil pengujian kekerasan baja HQ 760 setelah mendapat perlakuan temper dapat diamati pada tabel 2 .

Terlihat bahwa variasi suhu temper terbaik terletak pada rentang suhu antara $150{ }^{\circ} \mathrm{C} \mathrm{s} / \mathrm{d}$ $250{ }^{\circ} \mathrm{C}$. Dan waktu tahan temper terbaik terdapat pada rentang $30 \mathrm{~s} / \mathrm{d} 60$ menit. Dari data yang diperoleh seperti yang terlihat pada tabel, ternyata terdapat pengaruh suhu temper dan waktu tahan terhadap kekerasan baja HQ 760.

Tabel 2. Pengujian kekerasan baja HQ 760 pada beberapa variasi suhu dan waktu tahan . Nilai kekerasan dinyatakan dalam VHN.

\begin{tabular}{|c|c|c|c|}
\hline \multirow{2}{*}{$\begin{array}{c}\text { Suhu } \\
\text { temper }\end{array}$} & \multicolumn{3}{|c|}{ Waktu tahan ( menit ) } \\
\cline { 2 - 4 }$\left({ }^{\circ} \mathrm{C}\right)$ & 30 & 60 & 180 \\
\hline 150 & 542.867 & 496.21 & 456.116 \\
\hline 200 & 472.518 & 384.824 & 352.977 \\
\hline 250 & 413.303 & 316.151 & 297.947 \\
\hline 350 & 405.898 & 278.449 & 303.266 \\
\hline 600 & 242.655 & 242.925 & 236.554 \\
\hline
\end{tabular}

Keausan sebagai berkurangnya masa atau volume benda uji setelah mengalami penggesekan (pengerusan) akibat kontak antara revolving disk dan benda uji dapat dihitung dengan persamaan 2. Hasil pengukuran dan perhitungan dengan persamaan tersebut dapat dilihat pada tabel 3. 


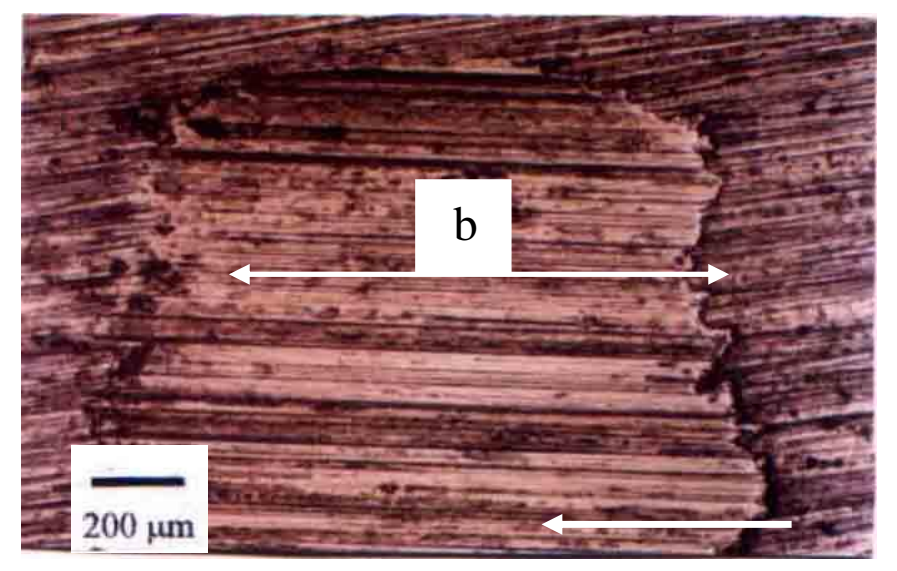

Gambar 2 Bentuk gerusan dan Panjang Alur $b$

Tabel 3 Pengujian keausan raw material dan setelah dihardening.

\begin{tabular}{|c|c|c|c|c|c|}
\hline PERLAKUAN & $\begin{array}{c}\text { SUHU } \\
\left({ }^{\circ} \mathrm{C}\right)\end{array}$ & $\begin{array}{l}\text { WAKTU } \\
\text { ( menit ) }\end{array}$ & $\begin{array}{c}\text { V hilang } \\
\left(\mathrm{mm}^{3}\right)\end{array}$ & $\begin{array}{c}\text { M hilang } \\
\text { (gr/det) }\end{array}$ & $\begin{array}{c}\text { M rata-rata } \\
\text { kolom }\end{array}$ \\
\hline \multirow{3}{*}{ BHN DASAR } & & & 0.1407 & 1.1721 & \multirow{3}{*}{1.3160} \\
\hline & & & 0.1836 & 1.5297 & \\
\hline & & & 0.1495 & 1.2461 & \\
\hline \multirow{3}{*}{ HARDENING } & \multirow{3}{*}{845} & \multirow{3}{*}{30} & 0.0193 & 0.1608 & \multirow{3}{*}{0.1344} \\
\hline & & & 0.015 & 0.1252 & \\
\hline & & & 0.0141 & 0.1172 & \\
\hline
\end{tabular}

Tabel 4 Pengujian keausan setelah perlakuan tempering dengan variasi suhu temper dan waktu.

\begin{tabular}{|c|c|c|c|c|c|}
\hline PERLAKUAN & $\begin{array}{c}\text { SUHU } \\
\left({ }^{\circ} \mathrm{C}\right)\end{array}$ & $\begin{array}{l}\text { WAKTU } \\
\text { (menit) }\end{array}$ & $\begin{array}{c}\mathrm{V} \\
\text { hilang } \\
\left(\mathrm{mm}^{3}\right)\end{array}$ & $\begin{array}{c}\mathrm{M} \\
\text { hilang } \\
\text { (gr/det) }\end{array}$ & $\begin{array}{l}\mathrm{M} \text { rata- } \\
\text { rata } \\
\text { kolom }\end{array}$ \\
\hline \multirow{4}{*}{$\begin{array}{c}\mathrm{T} \\
\mathrm{E} \\
\mathrm{M}\end{array}$} & \multirow{9}{*}{150} & \multirow{3}{*}{30} & $\begin{array}{c}0.016 \\
\end{array}$ & 0.1335 & \multirow{3}{*}{0.1492} \\
\hline & & & 0.0217 & 0.1807 & \\
\hline & & & 0.016 & 0.1335 & \\
\hline & & \multirow{3}{*}{60} & 0.0368 & 0.3064 & \multirow{3}{*}{0.1840} \\
\hline \multirow{2}{*}{$\begin{array}{l}\mathrm{P} \\
\mathrm{E}\end{array}$} & & & 0.0078 & 0.0651 & \\
\hline & & & 0.0217 & 0.1807 & \\
\hline $\mathrm{R}$ & & \multirow{3}{*}{180} & 0.0193 & 0.1608 & \multirow{3}{*}{0.1398} \\
\hline \multirow{11}{*}{$\begin{array}{l}\mathrm{I} \\
\mathrm{N} \\
\mathrm{G}\end{array}$} & & & 0.016 & 0.1335 & \\
\hline & & & 0.015 & 0.1252 & \\
\hline & \multirow{9}{*}{200} & \multirow{3}{*}{30} & 0.0106 & 0.0885 & \multirow{3}{*}{0.0930} \\
\hline & & & 0.0114 & 0.0952 & \\
\hline & & & 0.0114 & 0.0952 & \\
\hline & & \multirow{3}{*}{60} & 0.0123 & 0.1022 & \multirow{3}{*}{0.1235} \\
\hline & & & 0.0141 & 0.1171 & \\
\hline & & & 0.0181 & 0.1512 & \\
\hline & & \multirow{3}{*}{180} & 0.0205 & 0.1705 & \multirow{3}{*}{$0.148 \mathrm{c}$} \\
\hline & & & 0.015 & 0.1251 & \\
\hline & & & 0.0181 & 0.1512 & \\
\hline
\end{tabular}




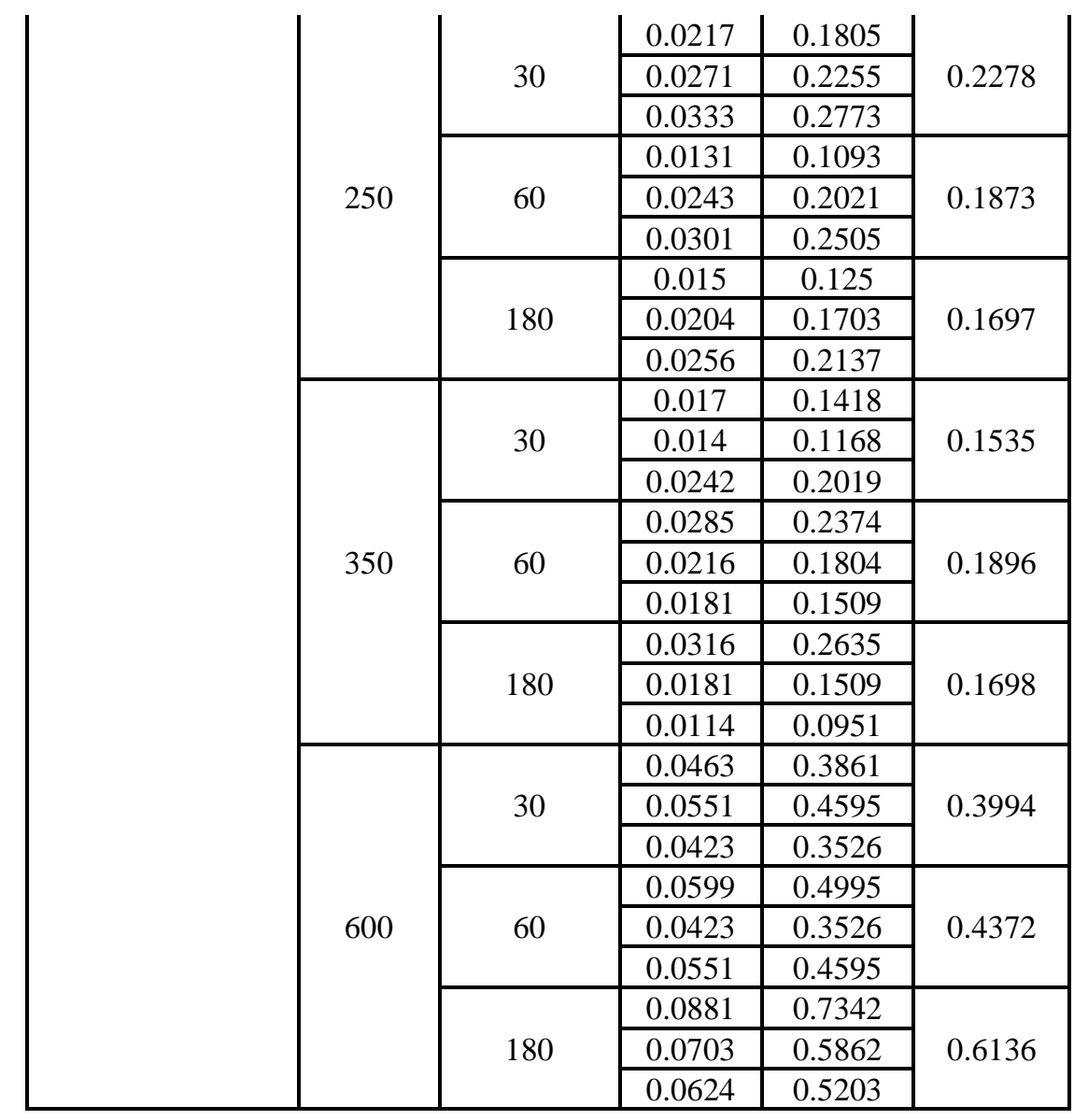

Dari tabel diatas terlihat bahwa laju pengausan baja HQ 760 sebelum mendapat perlakuan panas adalah 1,316 gr/dt. Setelah mendapat perlakuan panas quenching maka laju pengausannya menjadi $0,134 \mathrm{gr} / \mathrm{dt}$. Terjadi peningkatan daya tahan aus benda uji yang sangat tinggi.

Setelah perlakuan panas quenching yang dilanjutkan dengan perlakuan panas tempering dengan berbagai variasi suhu temper dan waktu tahan, maka diperoleh laju pengausan benda uji yang bervariasi juga. Laju pengausan terendah terjadi pada benda uji yang distemper pada suhu $200^{\circ} \mathrm{C}$ dengan waktu tahan 30 menit yaitu sebesar 0,093 gr/dt. Sedangkan laju pengausan tertinggi terjadi pada benda uji yang distemper pada suhu $600^{\circ} \mathrm{C}$ dengan waktu tahan 180 menit yaitu sebesar $0,613 \mathrm{gr} / \mathrm{dt}$.

Secara keseluruhan dari tabel diatas dapat dilihat bahwa terjadi perobahan laju pengausan benda uji setelah mendapat perlakuan panas quenching yang dilanjutkan dengan perlakuan tempering.

\section{KESIMPULAN DAN SARAN}

\section{A. Kesimpulan}

Dari penelitian yang telah dilakukan dapat ditarik kesimpulan sebagai berikut :

1. Baja HQ 760 dapat ditingkatkan kekerasannya dengan perlakuan panas Quenching yang lanjutkan denga perlakuan panas tempering. Hasil pengujian kekerasan terbaik di peroleh dari proses temper pada variasi suhu temper terletak pada rentang suhu antara $150^{\circ} \mathrm{C} \mathrm{s} / \mathrm{d} 250^{\circ} \mathrm{C}$. Dan waktu tahan temper terbaik terdapat pada rentang 30 s/d 60 menit.

2. Temperatur temper juga berpengaruh terhadap daya tahan aus baja HQ 760 . Dari pengujian diperoleh bahwa terjadi peningkatan yang signifikan daya tahan aus benda uji setelah mendapat perlakuan panas tempering, jika dibandingkan dengan ketahanan aus bahan dasar.

\section{B. Saran}

Berdasarkan kepada hasil penelitian yang telah dilakukan, maka ada beberapa saran 
yang dapat diberikan untuk penelitian berikutnya :

1. Perlu pengamatan yang cermat terhadap temperatur tahan tempering yang digunakan pada penelitian ini. Supaya didapatkan hasil pengujian terhadap kekerasan dan daya tahan aus yang lebih akurat.

2. Untuk mendapatkan bahan yang memiliki syarat angka kekerasan yang tinggi dan laju keausan yang rendah, maka perlakuan panas tempering yang harus dilakukan adalah pada interval suhu temper $150^{\circ} \mathrm{C}$ s $/ \mathrm{d} 250^{\circ} \mathrm{C}$.

3. Coba lakukan penelitian lebih lanjut terhadap pengaruh temperatur tempering dan waktu tahan terhadap kekerasan dan daya tahan aus dengan variasi waktu tahan yang nlebih banyak lagi, untuk mendapatkan hasil pengukuran yg lebih akurat.

\section{DAFTAR PUSTAKA}

ASM Handbook, 1990, Failure Analysis and Prevention, Vol.11, ASM International, Material Park, Ohio.

Colancelo, V.J., Heiser, F.A., 1989, "Analysis of Metallurgical Failures", John Wiley \& Sons, Singapore

Kalpakjian,S., 1985, Manufacturing Processes for Engineering Materials, Addison-Wisley Publishing Company, Massachusetts.

Lakhtin,Y., 1973, Engineering Phisical Metallurgy, Foreign Languages Publishing House, Moscow

Rabinowicz,E., 1995. Friction and Wear of Materials, $2^{\text {nd }}$ edition, John Willey and Sons, Inc., New York.

Surdia,T., dan Saito,S., 1999, Pengetahuan Bahan Teknik, Pradnya Paramita, Jakarta.

Shackelford,J.F.,1996, Introduction to Materials Science for Engineers, $4^{\text {th }}$ edition, Prentice Hall Inc., New York.

Van Vlack, Lawrence H., 1992, "Ilmu dan Teknologi Bahan”, Erlangga, Jakarta. 